\title{
Adherence to routine use of pharmacological prophylaxis of heterotopic ossification after total hip arthroplasty: results from an Italian multicenter, prospective, observational survey
}

\author{
Michele Barbato • Ezio D'Angelo • Giuseppina Di Loreto • Angelo Menna • \\ Alexander Di Francesco • Vincenzo Salini · Umberto Zoppi • Lino Cavasinni • \\ Pancrazio La Floresta • Carlo Luca Romanò
}

Received: 20 June 2011/ Accepted: 30 January 2012/Published online: 23 February 2012

(C) The Author(s) 2012. This article is published with open access at Springerlink.com

\begin{abstract}
Background In spite of the proven efficacy of pharmacological prophylaxis of heterotopic ossification following total hip arthroplasty, its routine use is still debated, and no data are available regarding the adherence to its administration in clinical practice.

Materials and methods In this prospective, observational, multicenter study, 480 consecutive patients operated on for primary total hip arthroplasty during the year 2009 were followed radiographically for 12 months after surgery in order to assess the incidence of periprosthetic heterotopic ossification. Surgeons were free to choose whether to administer pharmacological prophylaxis, and were asked to keep a record of the duration of the prophylaxis (if used) or the reasons for not using it. To facilitate the statistical analysis, all of the participating centers agreed to use only one drug (celecoxib) that had already proven to be effective.
\end{abstract}

M. Barbato · E. D’Angelo - G. Di Loreto

Deptartment of Orthopaedics and Traumatology, Ospedale G.

Bernabeo, Ortona, Italy

e-mail: michele.barbato@libero.it

\section{A. Menna}

Università degli Studi di Chieti "G. d'Annunzio", Bari, Italy

\footnotetext{
A. Di Francesco

Deptartment of Orthopaedics and Traumatology,

Ospedale San Salvatore, L'Aquila, Italy

V. Salini

Deptartment of Orthopaedics and Traumatology,

Policlinico SS. Annunziata, Chieti, Italy

U. Zoppi

Deptartment of Orthopaedics and Traumatology,

Ospedale G. Mazzini, Teramo, Italy
}

Results 368 patients were administered celecoxib and 112 patients did not receive any prophylaxis. Reported reasons for not administering celecoxib prophylaxis were the surgeon's opinion that prophylaxis was not needed on a routine basis $(84 / 112$ patients, $75 \%)$, previous history of gastrointestinal bleeding (17.8\%), and concomitant cardiorenal pathologies $(7.1 \%)$. The overall incidence of heterotopic ossification in the celecoxib-treated patients was $23 \%$ (no cases of Brooker grade 3 or 4 ossifications), compared to $55 \%$ in the untreated patients (Brooker grade 3 and 4: 8.9\%). Multivariate analysis showed that celecoxib prophylaxis was the single most important variable when predicting the occurrence of heterotopic ossification. Conclusions This study confirms the efficacy and tolerability of celecoxib for the prophylaxis of heterotopic ossification after total hip arthroplasty, and shows how the surgeon's belief that routine prevention is not required still

\footnotetext{
L. Cavasinni

Deptartment of Orthopaedics and Traumatology,

Ospedale Civile SS Immacolata, Sulmona, Italy

P. La Floresta

Deptartment of Orthopaedics and Traumatology,

Ospedale Cardarelli, Campobasso, Italy

C. L. Romanò ( $\square)$

Dipartimento di Chirurgia Ricostruttiva e delle Infezioni Osteo-articolari, Istituto Ortopedico I.R.C.C.S. Galeazzi,

Via Riccardo Galeazzi, 4, 20161 Milano, Italy

e-mail: carlo.romano@grupposandonato.it
} 
plays an important role in the determination of this complication, together with the fear of possible unwanted side effects.

Keywords Heterotopic ossification - Hip - Total hip arthroplasty · Prophylaxis · Prevention · Celecoxib · Italy

\section{Introduction}

Despite the evidence that heterotopic ossification (HO) can occur with an incidence ranging from 15 to $90 \%$ after conventional total hip arthroplasty (THA), and that about one-quarter of those patients will develop severe HO (Brooker [1] grades 3 and 4) which may be associated with impaired range of motion (ROM) at the hip joint and decreased functional outcome [2-5], a recent review article has suggested that routine $\mathrm{HO}$ prophylaxis is not warranted for routine THA [6], while it has been advocated for all surface replacements, given the higher incidence of complications compared to that for THA [7].

Several patient-related risk factors have been implicated in the development of HO after THA, such as age, male sex, hypertrophic osteoarthritis, ankylosing spondylitis, diffuse idiopathic skeletal hyperostosis, and history of $\mathrm{HO}$ $[3,8,9]$. However, since soft-tissue trauma is the main initiating factor in HO development [10, 11], and given the fact that HO may develop even in the absence of any known risk factor, the question of how to determine whether a patient should receive $\mathrm{HO}$ prophylaxis remains unresolved.

Low-dose irradiation after total hip arthroplasty has been reported to be effective in the prevention of $\mathrm{HO}[12$, 13], but extensive use of irradiation is limited by logistic problems, costs, and concerns about irradiating a vast population of patients. On the contrary, nonsteroidal antiinflammatory drugs like indomethacin provide easy-to-use and effective prophylaxis that can be administered in any hospital, even though side effects can limit its use [14-18]. As a valid alternative, celecoxib has been previously reported to be as effective as indomethacin but with fewer side effects [19], and to be better than ibuprofen [20].

In spite of this large body of evidence in favor of pharmacological prophylaxis, there is still a lack of consensus as to the need for extensive prevention of $\mathrm{HO}$ after THA.

The aim of this prospective, multicenter study was to observe adherence to the routine use of pharmacological prophylaxis of $\mathrm{HO}$ after primary THA in six orthopedic wards in two Italian central regions (Abruzzo and Molise), and to correlate that with the incidence of $\mathrm{HO}$.

\section{Materials and methods}

This study, performed under the aegis of GAMOT (Gruppo Abruzzo-Molise Ortopedici e Traumatologi), included 504 patients (126 males and 378 females) who were affected by hip osteoarthritis and were undergoing surgery to implant a cementless total hip arthroplasty on six orthopedic wards in Italy [Ospedale S. Salvatore, L'Aquila (AQ): 95 patients; Ospedale di Sulmona (SU): 86; Ospedale G. Bernabeo, Ortona (OR): 83; Ospedale di Teramo (TE): 83; Ospedale di Campobasso (CB): 82; Ospedale SS. Annunziata, Chieti (CH): 75] during the year 2009. Twelve (2.4\%) of these patients were lost to follow-up and so were not included in this review.

All the patients gave their informed written consent to collect their data prior to being included into this prospective, observational, multicenter study. The study was authorized by the local ethical committee and performed in accordance with the ethical standards of the 1964 Declaration of Helsinki as revised in 2000.

Exclusion criteria were previous surgery on the same hip, ankylosing spondilitis, diffuse idiopathic skeletal hyperostosis, neurologic diseases-all conditions that are known or suspected to increase the risk of development of heterotopic ossification [21, 22]. No patient received radiotherapy after the THA implant for HO prevention.

Preoperative diagnosis, surgical approach (posterolateral or direct lateral), HO prophylaxis, and its side effects were evaluated by a local investigator on each orthopedic ward. Surgeons were left free to choose whether or not to administer pharmacological prophylaxis of $\mathrm{HO}$ on the basis of their experience and their clinical judgement, but for those patients who did not receive prophylaxis, the surgeons were asked to make a record of the reason for their choice. To unify the data in this observational study and allow further statistical analysis, all of the participating centers agreed to use only celecoxib for the pharmacological prophylaxis of $\mathrm{HO}$.

Heterotopic ossification was evaluated by a radiologist blinded to the treatment the patient received. The grading of heterotopic ossification was performed using anteroposterior radiographs of the hip at 12 months after surgery, according to the classification of Brooker et al. [1]. This system classifies the absence of heterotopic bone formations as grade 0 , the presence of islands of bone within the soft tissues of the treated hip as grade I, the occurrence of bone spurs and a gap between opposing bone surfaces of $>1 \mathrm{~cm}$ as grade II, the presence of bone spurs and a gap of $<1 \mathrm{~cm}$ as grade III, and a bridge of bone across the joint as grade IV. Heterotopic ossification of grade III or more is associated with increasing impairment of range of motion and function. 
Patients for whom the treatment was stopped because of the occurrence of side effects were not included in the statistical evaluation of heterotopic bone formation.

To analyze sample characteristics, Fisher's exact test was used for categorical variables or linear regression models for continuous variables. Statistical significance was defined as a $P$ value of less than 0.05 , and $95 \%$ CI.

\section{Results}

At follow-up, 492 patients were available; 380 (77.2\%) patients were administered pharmacological prophylaxis (celecoxib $200 \mathrm{mg}$ twice per day, for $17 \pm 3$ days, a minimum of 14 and a maximum of 20 days after surgery, starting the day after the surgical procedure in all cases). Twelve (3.2\%) patients treated with celecoxib reported minor gastrointestinal side effects that required treatment discontinuation after a mean of 9 days (range 7-15 days) from the start of treatment, and were not included in the review of $\mathrm{HO}$ any further. No patient received indomethacin.

One hundred twelve $(22.8 \%)$ patients did not receive any prophylaxis for HO; reported reasons for not administering prophylaxis were the surgeon's opinion that prophylaxis was not needed on a routine basis $(84 / 112$ patients, $75 \%$ ), a previous history of gastrointestinal bleeding $(20 / 112 ; 17.9 \%)$, or concomitant cardiorenal pathologies $(8 / 112 ; 7.1 \%)$ (Fig. 1).

The overall incidence of heterotopic ossification in the celecoxib-treated patients was $23.1 \%$ (85/368, no Brooker grade 3 or 4 ossifications), compared to $55.3 \%(62 / 112)$ in the untreated group. In the latter, 10/112 (8.9\%) patients showed Brooker grade 3 and 4 ossification. Grades 1, 2, 3, and $4 \mathrm{HO}$ were respectively seen in $27(24.1 \%), 25$ $(22.3 \%), 8(7.1 \%), 2(1.8 \%)$ untreated patients; grades 1 and $2 \mathrm{HO}$ were observed in $70(19.0 \%)$ and $15(4.1 \%)$ of the patients treated with celecoxib (Fig. 2). The overall

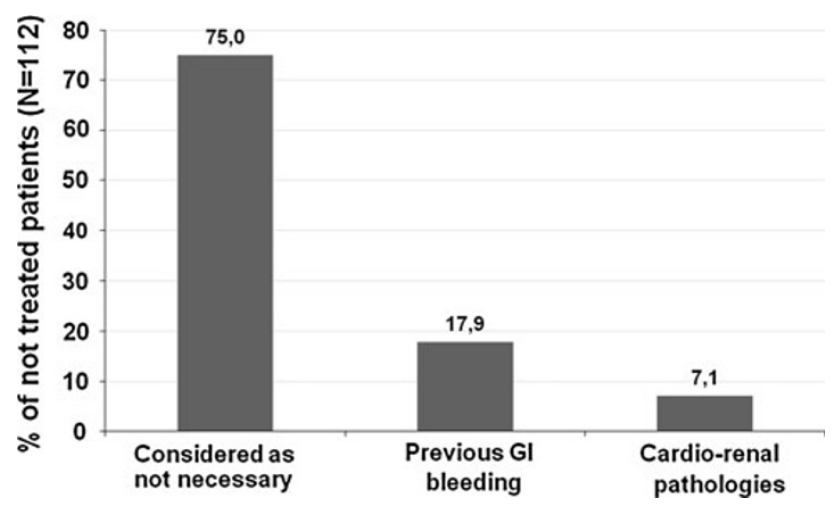

Fig. 1 Surgeons self-reported reasons for not administering pharmacological prophylaxis in patients that underwent total hip replacement in this study $(N=112)$

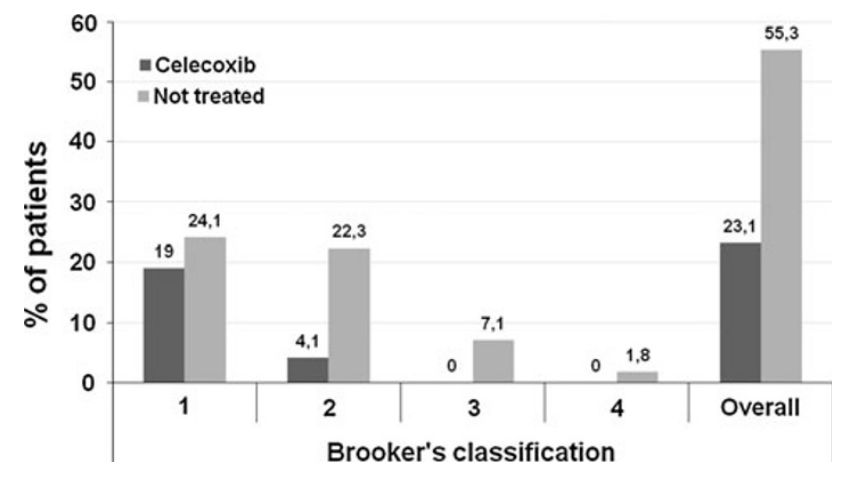

Fig. 2 Incidence of heterotopic ossification in the celecoxib $(N=$ $368)$ and in the untreated $(N=112)$ groups

difference in $\mathrm{HO}$ in the two groups (23 vs. $55 \%$ ) was statistically significant $(P<0.0001)$.

Logistic regression showed that the occurrence of HO did not correlate with sex $(P=0.66)$, preoperative diagnosis $(P=0.14)$, hospital $(P=0.24)$, or surgical approach $(P=0.09)$, while celecoxib prophylaxis was the single most important variable in predicting the occurrence of heterotopic ossification $(P<0.0001$; O.R.: 4.1 ; CI: 2.6-6.4).

\section{Discussion}

There is a large body of evidence on the incidence of $\mathrm{HO}$ after THA; in the literature, it ranges from 15 to $90 \%$, with the rate of severe $\mathrm{HO}$ (Brooker grades 3 and 4) at around $10 \%$, in the absence of adequate prophylaxis [2]. Severe HO have been shown to be associated with impaired range of motion (ROM) at the hip joint and decreased functional outcome [3-5]. Even though several patient-related risk factors for developing ectopic ossification are well known [18, 22], as stated by Kolbl and Knelles et al. [13]: "on an absolute scale considerably more patients without risk factors develop heterotopic ossification because the number of patients with risk factors is low compared to all patients receiving total hip replacement. In this respect, prophylactic treatment after total hip replacement seems advocated for all patients." Contrary to this statement, other authors have recently suggested that "there is currently little evidence to support the routine use of prophylaxis for heterotopic ossification in arthroplasty patients" [6], while pharmacological prophylaxis has been advocated for all surface replacements, given the higher incidence of the complication compared to THA [7]. More recently, $\mathrm{HO}$ prophylaxis has also been advocated after hip arthroscopy for femoroacetabular impingement syndrome [23].

This is, to our knowledge, the first prospective, observational, multicenter study ever performed to investigate 
the actual application of routine pharmacological prophylaxis after THA in patients without known risk factors for $\mathrm{HO}$ in different orthopedic wards of general hospitals in Italy and in Europe.

The incidence of $\mathrm{HO}$ observed in the present study in patients who were not treated with prophylactic measures and did not have any known risk factor is perfectly in keeping with those previously reported in the literature. Our study confirms the efficacy of administering celecoxib postoperatively to prevent this complication and the relatively low rate of side effects and dropouts connected with this prophylaxis. Our data also illustrate the reported reasons for not treating patients on a routine basis. In this regard, the belief that routine HO prophylaxis is not justified for patients without known risk factors for $\mathrm{HO}$ is the main reported cause for not administering pharmacological prophylaxis in our study. This may be due to the conflicting statements in the literature that are in favor of [13-20] or against the routine use of prophylaxis [6]. Other reported reasons for not performing pharmacological prophylaxis include risk factors for potential side effects connected with the use of anti-inflammatory drugs [24]. The importance of minimizing possible side effects in the clinical setting may also explain the universal preference of all the surgeons included in this survey for celecoxib rather than other possible nonsteroidal anti-inflammatory drugs. In fact, celecoxib has previously been reported to be equally effective but associated with fewer side effects than indomethacin [19, 25], while it has proven more effective than ibuprofen [20]. Considering the reasons for not administering pharmacological prophylaxis critically, in the light of the most recent reports on the safety of celecoxib used in association with proton pump inhibitors, even in patients with severe gastrointestinal risk factors [26, 27], it is questionable as to whether previous gastrointestinal bleeding should be considered a contraindication to pharmacological prophylaxis of $\mathrm{HO}$ with celecoxib. On the other hand, there is no clear evidence that short-term administration (less than 20 days) of celecoxib or any other nonsteroidal anti-inflammatory drugs can have serious side effects on the cardiorenal apparatus [28].

Limits of the present study include:

- The absence of a comparator group of patients treated with other nonsteroidal anti-inflammatory drugs

- The absence of a placebo control group

- The patient's allocation to the two groups based on the surgeon's choice

- The lack of complete information on comorbidities and their relative incidences

- The lack of information on possible subclinical side effects of the prophylaxis (e.g., the incidence of lower gastrointestinal tract bleeding)
- The lack of demonstration that prophylactic treatment with lower doses or a shorter duration would have been equally effective

In spite of these limitations, the present study confirms the efficacy and safety of pharmacological prophylaxis of $\mathrm{HO}$ with a selective cycloxygenase- 2 inhibitor, and favors the routine administration of this prophylaxis after THAeven in patients without known risk factors for this complication, given the high incidence of complications in untreated patients.

Acknowledgments We wish to thank the doctors S. Flamini (L'Aquila), V. Francione and C. Verdecchia (Teramo), F.P. Ciampa and P. Giuliani (Pescara), L. Guerra (Pescara), D. Palmieri (Pescara), D. Borri, and L. Kontochristos (Sulmona) for their help in recruiting and following-up the patients.

\section{Conflict of interest None.}

Open Access This article is distributed under the terms of the Creative Commons Attribution License which permits any use, distribution, and reproduction in any medium, provided the original author(s) and the source are credited.

\section{References}

1. Brooker AF, Bowerman JW, Robinson RA et al (1973) Ectopic ossification following total hip replacement. Incidence and a method of classification. J Bone Joint Surg Am 55:1629

2. Neal B, Gray H, MacMahon S et al (2002) Incidence of heterotopic bone formation after major hip surgery. ANZ J Surg 72:808

3. Ahrengart L (1991) Periarticular heterotopic ossification after total hip arthroplasty. Risk factors and consequences. Clin Orthop Relat Res 263:49-58

4. Neal B (2003) Effects of heterotopic bone formation on outcome after hip arthroplasty. ANZ J Surg 73:422

5. Pohl F, Seufert J, Tauscher A et al (2005) The influence of heterotopic ossification on functional status of hip joint following total hip arthroplasty. Strahlenther Onkol 181:529

6. Board TN, Karva A, Board RE et al (2007) The prophylaxis and treatment of heterotopic ossification following lower limb arthroplasty. J Bone Joint Surg Br 89:434

7. Rama KRBS, Vendittoli PA, Ganapathi M, Borgmann R, Roy A (2009) Heterotopic ossification after surface replacement and total hip arthroplasty. J Arthroplasty 24(2):256-262

8. Ahrengart L, Lindgren U (1993) Heterotopic bone after hip arthroplasty. Defining the patient at risk. Clin Orthop Relat Res 293:153-159

9. Eggli S, Woo A (2001) Risk factors for heterotopic ossification in total hip arthroplasty. Arch Orthop Trauma Surg 121:531

10. Ekelund A, Brosjo O, Nilsson OS (1991) Experimental induction of heterotopic bone. Clin Orthop Relat Res 263:102-112

11. Kaplan FS, Glaser DL, Hebela N et al (2004) Heterotopic ossification. J Am Acad Orthop Surg 12:116

12. Ayers DC, Evarts C, Parkinson JR (1986) The prevention of heterotopic ossification in high risk patients by low dose radiation therapy after total hip arthroplasty. J Bone Joint Surg Am 68:1423

13. Kolbl O, Knelles D, Barthel T et al (1998) Preoperative irradiation versus the use of nonsteroidal anti-inflammatory drugs for prevention of heterotopic ossification following total hip 
replacement: the results of a randomized trial. Int J Radiat Oncol Biol Phys 42:397

14. Almasbakk K, Roysland P (1977) Does indomethacin (IMC) prevent postoperative ectopic ossification in total hip replacement. Acta Orthop Scand 48:556-560

15. Cella JP, Salvati EA, Sculco TP (1988) Indomethacin for the prevention of heterotopic ossification following total hip arthroplasty: effectiveness, contraindications an adverse effects. J Arthroplasty 3:229

16. Randelli G, Romanò CL, Visentin O (1990) Rigidità d'anca postoperatoria da ossificazioni. Lo Scalpello IV 2:167

17. Kjaersgaard-Andersen P, Schmidt SA (1986) Indomethacin for prevention of ectopic ossification after hip arthroplasty. Acta Orthop Scand 57:12

18. Ritter MA, Gioe TJ (1982) The effect of indomethacin on paraarticular ectopic ossification following total hip arthroplasty. Clin Orthop 167:113

19. Romanò CL, Duci D, Romanò D et al (2004) Celecoxib versus indomethacin in the prevention of heterotopic ossification after total hip arthroplasty. J Arthroplasty 19:14

20. Saudan M, Saudan P, Perneger T, Riand N, Keller A, Hoffmeyer $P$ (2007) Celecoxib versus ibuprofen in the prevention of heterotopic ossification following total hip replacement. J Bone Joint Surg 89(B-2):155-159

21. Ritter MA, Vaugham RB (1977) Ectopic ossification after total hip arthroplasty: predisposing factors, frequency, and effect on results. J Bone Joint Surg Am 59:345
22. Blasingame JP, Resnick D, Coutts RD, Danzig LA (1981) Extensive spinal osteophytosis as a risk factor for heterotopic bone formation after total hip arthroplasty. Clin Orthop 161:191

23. Randelli F, Pierannunzii L, Banci L, Ragone V, Aliprandi A, Buly R (2010) Heterotopic ossifications after arthroscopic management of femoroacetabular impingement: the role of NSAID prophylaxis. J Orthop Traumatol 11(4):245-250

24. Fransen M, Neal B (2004) Non-steroidal anti-inflammatory drugs for preventing heterotopic bone formation after hip arthroplasty. Cochrane Database Syst Rev 3:CD001160

25. Xue D, Zheng Q, Li H, Qian S, Zhang B, Pan Z (2011) Selective COX-2 inhibitor versus nonselective COX-1 and COX-2 inhibitor in the prevention of heterotopic ossification after total hip arthroplasty: a meta-analysis of randomised trials. Int Orthop 35(1):3-8

26. Chan FK, Wong VW, Suen BY, Wu JC, Ching JY, Hung LC, Hui AJ, Leung VK, Lee VW, Lai LH, Wong GL, Chow DK, To KF, Leung WK, Chiu PW, Lee YT, Lau JY, Chan HL, Ng EK, Sung JJ (2007) Combination of a cyclo-oxygenase-2 inhibitor and a proton-pump inhibitor for prevention of recurrent ulcer bleeding in patients at very high risk: a double-blind, randomised trial. Lancet 369(9573):1621-1626

27. Lai LH, Chan FK (2009) Nonsteroid anti-inflammatory drug-induced gastroduodenal injury. Curr Opin Gastroenterol 25(6):544-548

28. Jones P, Lamdin R (2010) Oral cyclo-oxygenase 2 inhibitors versus other oral analgesics for acute soft tissue injury: systematic review and meta-analysis. Clin Drug Investig 30(7):419-437 